\title{
Life skills, employability and training for disadvantaged youth: Evidence from a randomized evaluation design
}

\author{
Pablo Ibarraran ${ }^{1 *}$, Laura Ripani ${ }^{2}$, Bibiana Taboada ${ }^{2}$, Juan Miguel Villa ${ }^{3}$ and Brigida Garcia ${ }^{4}$
}

\footnotetext{
* Correspondence: pibarraran@iadb.org ${ }^{1}$ Inter-American Development Bank (IDB), Washington, DC and IZA Bonn, Germany

Full list of author information is available at the end of the article
}

\begin{abstract}
This paper presents an impact evaluation of a revamped version of the Dominican Republic's youth training program Juventud y Empleo. The paper analyzes the impact of the program on traditional labor market outcomes and on outcomes related to youth behavior and life style, expectations about the future and socio-emotional skills. In terms of labor market outcomes, the program has a positive impact on job formality for men of about 17 percent and there is also a seven percent increase in monthly earnings among those employed. However, there are no overall impacts on employment rates. Regarding non-labor market outcomes, the program reduces teenage pregnancy by five percentage points in the treatment group (about 45 percent), which is consistent with an overall increase in youth expectations about the future. The program also has a positive impact on non-cognitive skills as measured by three different scales. Scores improve between 0.08 and 0.16 standard deviations with the program. Although recent progress noted in the literature suggests that socio-emotional skills increase employability and quality of employment, the practical significance of the impacts is unclear, as there is only weak evidence that the life skills measures used are associated to better labor market performance. This is an area of growing interest and relevance that requires further research.

JEL codes: J24, J64, O15, O17.
\end{abstract}

Keywords: Impact evaluation; Dominican Republic; Youth training programs; Labor market outcomes; Employment; Life skills

\section{Introduction}

Youth training programs have been implemented in Latin America and the Caribbean (LAC) since the early 1990s. These programs target less-educated youth, a group that faces serious difficulties in achieving a successful insertion into the labor market, with the explicit aim of raising participants' job skills and matching them to suitable employers ${ }^{1}$. Drawing on lessons from evaluations of the Job Training Partnership Act in the United States and the Youth Training Scheme in Britain, these programs combine classroom training with a subsequent internship period of on-the-job work experience $^{2}$. The training programs have two basic premises: first, that the lack of basic technical and life skills determine the poor labor market insertion of the targeted youth i.e. low wages, informality and underemployment, and second, that these courses are 
successful in enhancing those skills ${ }^{3}$. There is also an underlying assumption that the economy has or is creating vacancies to be filled by program graduates ${ }^{4}$.

A salient characteristic of these programs is their emphasis on socio-emotional skills ${ }^{5}$, which have gained increasing importance in most of these projects (Ibarrarán and Rosas 2009; Gonzalez et al. 2011). Until recently, however, job training programs have included socio-emotional skills components in an ad hoc manner, based on scant qualitative evidence and without focusing too much on measuring these skills or the results of training in improving them. Recent evidence on the importance of non-cognitive skills both from econometric and qualitative analyses of determinants of success in the labor market show that employers value certain behaviors and attitudes that are linked to high-productivity workers (Heckman et al. 2006; Urzua 2009; Fazio 2011).

While conceptually socio-emotional skills are well defined, it has been difficult to measure and analyze them empirically. Recent literature has explored alternative measurements (Brunello and Schlotter 2011; Felfe et al. 2011), mostly for developed countries. However, there is a knowledge gap on how to measure socio-emotional skills in the LAC region and about the importance of such skills in explaining the labor market outcomes of youth, particularly disadvantaged youth. Furthermore, from a policy perspective, it is important to know whether and how socio-emotional skills can be acquired by young people in Latin America and the Caribbean.

One of the most innovative youth-training programs in LAC is the Dominican Republic's Youth and Employment Program, Juventud y Empleo (JE). JE was first designed in 1999 and is the first program of its type to have an experimental evaluation from its inception. This evaluation design has enabled program managers to learn from the implementation of the program and to use the evaluation findings to improve subsequent phases, in a virtuous cycle of evaluation and feedback. This cycle includes rigorous quantitative as well as qualitative evidence. In this way, the program has been modified to test new hypotheses.

While previous evaluations of this program have focused almost exclusively on the labor market impacts-namely, employment rate, labor earnings and quality of employment, which we also report on-this paper also takes a closer look at the mechanisms by which training is supposed to improve participants' labor market performance, specifically, by increasing the non-cognitive and socio-emotional skills with which they join the labor force. We also examine other important outcomes that can be attributed to training, such as the teenage pregnancy rate. Given the high teenage pregnancy rates in the Dominican Republic and the negative labor-market consequences of teenage pregnancy, this is an important outcome from a theoretical and a practical standpoint. Dominican teenagers receive little instruction in sex education. In the country, about 17 percent of females aged 15-19 years old already have children (Oficina Nacional de Estadística ONE 2008).

Evidence from the LAC region confirms the negative effects of teenage pregnancy on various socio-economic variables. In Mexico, in the short run, teenage pregnancy reduces years of schooling, school attendance and hours of work, while it increases marriage rates. In the long run, teenage pregnancy results in a loss in years of education and in lower income. It also contributes to a higher probability of being married and divorced (Acero-Gomez and Campos-Vazquez 2011). 
Our analysis is based on a sample of applicants for the cohort of trainees that participated in a version of the JE program that was modified as a result of the first impact evaluation. The cohort under study applied to receive training during 2008. We show that labor market impacts are mixed, with a negligible impact on overall employment and a substantial impact on job quality for men. We find positive impacts in terms of perceptions and expectations about the future, in particular for young women who simultaneously reduce their pregnancy rates considerably. We also document a positive impact of training on alternative measures of life skills, particularly leadership skills, conflict resolution, self-organization and persistency of effort. These skills, in particular persistency of effort, have been analyzed and the findings show that they improve labor market outcomes in developed countries (Heckman et al. 2006). The impact of those soft skills on labor market performance in developing countries is a rich area for future research.

The paper is organized as follows. After this introduction, Section 2 provides the specifics of the program, as well as a description of its previous evaluation. Section 3 describes the basic design features of this evaluation and the data collected. Section 4 presents the results, followed by conclusions in Section 5 .

\section{The juventud y empleo program}

\subsection{Description of the intervention}

The JE program is a Dominican active labor market program (ALMP) that aims to improve the labor market entry of youth between 16 and 29 years of age who did not complete high school. It has been in operation since 2001 and was the first job training program in Latin America to incorporate a randomized evaluation component when the project was designed.

The program offers a wide range of job training courses such as administrative assistant, baker, hair stylist, clerk, auto mechanic, bartender, and so on. The Ministry of Labor outsources the provision of training services to private training institutions (Centros Operadores del Sistema, COS) that are registered and approved by the national training institution (Instituto Nacional de Formación Técnico Profesional, INFOTEP). Courses of 225 hours are conducted in the COS facilities and split into two parts: 75 hours of basic or life skills training, and 150 hours of technical or vocational training. Basic skills training is meant to strengthen trainees' self- esteem and work habits, while vocational training is meant to address the technical training needs of local employers. Training at the COS is followed by an internship in a private sector firm, which should be contacted by the COS in order to develop training programs tailored to the firm's labor demand. Young people are identified by the COS according to their preferred vocation and the availability of the desired course. Once they reach 35 potential participants, the COS sends the names and identification numbers to the program coordinating unit (PCU), which randomly selects those who are offered the training course.

\subsection{Previous evaluations}

The first impact evaluation of this program (Card et al. 2011) was based on a sample of applicants of the second cohort of the JE program who applied to receive training in early 2004. Baseline data were collected from applicants prior to random assignment through registration forms completed at the COS. A follow-up survey was administered 
from May to July 2005; some 10 to 14 months after most trainees had finished their initial coursework. Simple comparisons between trainees in the follow-up survey and members of the control group show little impact on employment, although there is some evidence of a modest impact on wages and formality for men. Unfortunately, however, the randomized design of the JE evaluation was potentially compromised by the failure to include in the follow-up survey people who were originally assigned to receive training but failed to show up or attended only briefly.

Moreover, as is often the case in voluntary programs even under a well-implemented random assignment, compliance was not perfect: some of the lottery winners (intended to be treated) did not participate in the training either because they did not show up or they dropped out at some point. Some who were selected for the control group ended up taking the training as replacements of drop-outs and no-shows or for some other reason.

Card et al. (2011) addressed the problem caused by the failure to follow up on noshows through selection correction models and by showing with the baseline data that the characteristics of no-shows were similar to those of the replacements. They also excluded the reassigned controls from alternative specifications and the results held. The estimated impacts on employment are all fairly close to zero, and there are no statistically significant differences by gender, age, education, or geographic location. The estimated impacts on monthly earnings are fairly similar for men and women, and for younger and older workers, but they show interesting patterns by education and geographic location. If one compares better-educated applicants in Santo Domingo to all others the results are striking: this subgroup accounts for virtually all of the observed positive impact on monthly earnings ${ }^{6}$.

The only other impact evaluation with randomized design of a similar training program in Latin America - the Colombian Jóvenes en Acción program- was done by Attanasio et al. (2011). They conclude that the program, which was contemporary to JE and had the same components, raised earnings and employment, especially for women. Women offered training earned $18 \%$ more and had a 0.05 higher probability of employment than those not offered training, mainly in formal sector jobs ${ }^{7}$.

\section{Evaluation design}

This second evaluation focuses on a modified version of the program and its evaluation design. While the core of the project -two-stage training followed by an internship- is maintained and the evaluation is still based on random assignment, there are some important changes:

- COS are supposed to work closer to the firms that provide the internship in order to develop tailored courses to train people for real vacancies ${ }^{8}$.

- The life skills section of the training was revamped as firms argued that what they valued most from training were the general job-readiness and life skills rather than the technical training'.

- Random assignment was done on a larger sample for each course (20 treatments, 15 controls).

- Follow-up was improved in terms of sample size, survey instruments and quality controls of the field work. 
Table 1 Classification of participants by assignment and treatment status

\begin{tabular}{lll}
\hline & $\begin{array}{l}\text { Selected in the lottery, } \\
\mathbf{Z i}=\mathbf{1}\end{array}$ & $\begin{array}{l}\text { Not selected in the lottery, } \\
\mathbf{Z i}=\mathbf{0}\end{array}$ \\
\hline Participated in the program, $\mathrm{Di}=1$ & "Complier" Beneficiaries & Replacements/Always Takers \\
Did not participate in the program, $\mathrm{Di}=0$ & No-shows, dropouts/Never Takers & "Complier" Control group \\
\hline Source: Authors. & &
\end{tabular}

Random assignment was applied on a group of potential participants identified by the COS that applied to the program and met the eligibility criteria ${ }^{10}$. The program received the information from the COS and verified that none of the applicants had been registered before. For each course, the COS submitted data on 35 eligible and interested young people, and the program managers at the PCU randomly selected and then divided them into two groups. The first one is formed by 20 young people who were offered the program. The second group is composed by the remaining 15 young people, who were assigned to the control group.

If young people offered the program did not respond or dropped out before the tenth day of ongoing classes, the COS could replace up to five slots with members of the control group. The replacements were supposed to be randomly selected by the PCU within the control group, and the PCU provided the names directly to the COS. However, in practice, the COS experienced some degree of discretion in selecting the replacements, which might have led to selection bias. This is why we focus on the original random assignment to estimate the impact of the program, where there were no concerns about selection bias.

Despite having an ideal initial configuration of the treatment and control groups due to successful randomization, there was imperfect compliance due to (non-random) decisions by $\mathrm{COS}$ and participants ${ }^{11}$. Introducing a general notation, let $\mathrm{Zi}$ represent the random assignment of each young person $\mathrm{i}$ where $\mathrm{Zi}=1$ are those randomly assigned to the treatment group and $\mathrm{Zi}=0$ are those randomly assigned to the control group. Similarly, let Di represent the final treatment status were $\mathrm{Di}=1$ are those who attended the course and $\mathrm{Di}=0$ those who did not do so. Table 1 clarifies the setting.

During the registration process, the program identified 10,309 applicants who met the selection criteria, with the distribution presented in Table 2, according to the administrative data.

Note that the number of never-takers equals the number of always-takers because the PCU tried to maintain the number of participants per course.

\subsection{Identification strategy}

Follow-up data were collected on a representative sample of all those who participated in the lottery and, thus, is suitable for the estimation of the impact of the program on those who won the lottery -to whom a course was randomly offered-. This is the Intention to Treat Effect (ITT) that estimates the impact of offering the JE program,

Table 2 Classification of treatment groups

\begin{tabular}{llll}
\hline & $\begin{array}{l}\text { Selected in the lottery, } \\
\mathbf{Z i}=\mathbf{1}\end{array}$ & $\begin{array}{l}\text { Not selected in the lottery, } \\
\mathbf{Z i}=\mathbf{0}\end{array}$ & Total \\
\hline Participated in the program, $\mathrm{Di}=1$ & 4,937 & 977 & 5,914 \\
Did not participate in the program, $\mathrm{Di}=0$ & 977 & 3,418 & 4,395 \\
TOTAL & 5,914 & 4,395 & 10,309 \\
\hline
\end{tabular}

Source: Administrative data. 
regardless of what happened after the random assignment. That is, some young people may have finally decided not to attend the courses or dropped out during the first week of classes, while some of those assigned to the control group may have ended up receiving the treatment.

Because the ITT yields the causal effect of $Z_{i}$, its estimation includes all the group of young people that participated in the random assignment, including those for whom $\mathrm{Di} \neq \mathrm{Zi}$, the pairs $D_{i}=1 \mid Z_{i}=0$ and $D_{i}=0 \mid Z_{i}=1$, formed by those who took the course although they were randomly assigned to the control group and those who did not show up or dropped out although they belonged to the treatment group, respectively ${ }^{12}$. Therefore, one may expect that the effect of offering JE becomes smaller to the extent that the proportion of those with $\mathrm{Di} \neq \mathrm{Zi}$ increases ${ }^{13}$.

Under certain conditions, it is also possible to estimate the impact of the program on the compliers, i.e. those who took the course because they were selected in the lottery ${ }^{14}$. Without loss of generality, in this paper we largely discuss the ITT estimates computed with standard ordinary least squares ${ }^{15}$.

\subsection{Baseline data}

The baseline data were collected at the registration stage at each COS. They were available for all those eligible and interested to participate in the program, a total of 10,309 young people. Table 3 shows some characteristics from the baseline survey and

Table 3 Basic characteristics at baseline

\begin{tabular}{|c|c|c|c|c|}
\hline Characteristic & $\begin{array}{l}Z i=1 \\
\text { (a) }\end{array}$ & $\begin{array}{l}Z i=0 \\
\text { (b) }\end{array}$ & $\begin{array}{l}\text { Difference (Zi) } \\
\text { (a) - (b) }\end{array}$ & $t$ \\
\hline Age & 22.03 & 21.99 & 0.04 & 0.59 \\
\hline Gender $($ male $=1)$ & 0.37 & 0.38 & -0.01 & -1.35 \\
\hline Marital status (married $=1$ ) & 0.24 & 0.24 & 0.00 & -0.03 \\
\hline Number of children & 0.71 & 0.70 & 0.01 & 0.42 \\
\hline Attend school (currently) & 0.23 & 0.23 & 0.01 & 0.76 \\
\hline Incomplete elementary & 0.20 & 0.20 & 0.00 & -0.3 \\
\hline Complete elementary & 0.05 & 0.05 & 0.00 & -0.2 \\
\hline Incomplete high school & 0.55 & 0.58 & -0.03 & 1.09 \\
\hline Complete high school & 0.04 & 0.03 & 0.00 & 0.79 \\
\hline More than high school & 0.00 & 0.00 & 0.00 & 0.02 \\
\hline Missing education & 0.04 & 0.04 & 0.00 & -0.65 \\
\hline No data on education & 0.11 & 0.12 & -0.01 & -1.19 \\
\hline Fraction with prior work experience & 0.20 & 0.22 & -0.02 & 1.37 \\
\hline Currently employed & 0.04 & 0.04 & 0.00 & 0.15 \\
\hline Currently salaried worker & 0.02 & 0.02 & 0.00 & -0.23 \\
\hline Currently unemployed & 0.53 & 0.52 & 0.00 & 0.28 \\
\hline ICV Score $(0 \text { to } 100)^{*}$ & 62.81 & 62.93 & -0.12 & -0.59 \\
\hline Urban areas & 0.89 & 0.89 & 0.00 & -0.47 \\
\hline Lives in Santo Domingo & 0.24 & 0.24 & 0.00 & 0.27 \\
\hline Receives remittances & 0.11 & 0.11 & 0.00 & -0.31 \\
\hline Observations & 5,914 & 4,395 & & \\
\hline
\end{tabular}

Source: JE baseline data and administrative records.

Note: Means, differences and t-statistics are calculated by linear regression with robust standard errors.

${ }^{* * *} \mathrm{p}<0.01,{ }^{* *} \mathrm{p}<0.05,{ }^{*} \mathrm{p}<0.1$. 
a t-statistic for equality of means between the $Z_{i}$ groups as an evidence of randomness. Most participants -62 percent-are women, and nearly all of those reporting some education have not completed high school. Ninety percent of participants live in urban areas and about a quarter live in Santo Domingo. The average age is 22 years. About 22 percent of individuals were attending school at the time of the baseline. As shown in the table's last column, random assignment was well implemented as all of the characteristics are balanced.

It is interesting to note that only 4 percent of young people declared being employed at the baseline prior to the beginning of the courses, and that 52 percent of them were unemployed, meaning that 44 percent were inactive. This may be due to the requirements of the selection process, which demanded that they be inactive or unemployed, and may also be an expression of the Ashenfelter's dip (Ashenfelter 1978), i.e. that both groups received a shock that increased unemployment levels right before the program started. According to the National Labor Force Survey (known as ENFT, Encuesta Nacional de Fuerza de Trabajo), in 2008 the employment rate in the Dominican Republic for young people 16 to 29 years old with less than complete high school education was 43 percent.

\subsection{Follow-up survey}

After the completion of the courses, a follow-up household survey was carried out between November 2010 and February 2011 (18 to 24 months after graduation) on a random sample of 5,000 out of the 10,309 young people who had initially registered ${ }^{16}$. This sample has 3,250 individuals from the treatment group and 1,750 from the control group.

The questionnaire for the follow-up household survey was put together by an interdisciplinary team from the Ministry of Labor of the Dominican Republic, the InterAmerican Development Bank and the World Bank. It includes 15 modules that collect data on household composition and socioeconomic characteristics, labor force participation ${ }^{17}$, labor history, assets, time use, JE courses and internship, consumption, health status, risk aversion, future expectations, pregnancy history, dwelling materials and basic skills, including non-cognitive skills and self-esteem.

About 80 percent of the sample were located at their households for the follow up survey, with virtually no difference between those selected and those not selected in the lottery (in the case of $Z_{i}=1$ and $Z_{i}=0,80.8$ and 80.4 percent were interviewed, respectively). This compares favorably to the first evaluation of JE, where the attrition rate was larger and unbalanced between beneficiaries and members of the comparison group (the attrition rates were 35 and 45 percent, respectively).

We verified the similarity of the interviewed treatment and control groups. We also compared the basic characteristics of those that were interviewed and those that were not. Additional file 1: Table S1 compares the sample of those intended to be interviewed and those finally interviewed. The original and the realized samples have similar characteristics at baseline. Nonetheless, comparing the original and realized groups on the same random assignment $\left(\mathrm{Z}_{\mathrm{i}}\right)$ there is a small imbalance in the poverty indicator (ICV) for the control group, but the differences are close to zero. Regarding the treatment group (column $(a)-(c)$ ), the most notable differences emerged in school attendance and location in urban areas, for which disparities are statistically significant but very small. Hence, we assume that attrition was random and that it affected equally both those selected and those not selected in the lottery. 
Table 4 Notification from COS by lottery results

\begin{tabular}{lllll}
\hline \multicolumn{5}{l}{ Were you notified to start the course? } \\
\hline \multicolumn{7}{l}{$\mathbf{Z i}=\mathbf{0}$} & & $\mathbf{Z i}=\mathbf{1}$ & \\
\hline Yes & 615 & $47.0 \%$ & 2,335 & $92.9 \%$ \\
No & 693 & $53.0 \%$ & 178 & $7.1 \%$ \\
Total & 1,308 & & 2,513 & \\
\hline
\end{tabular}

Source: Follow-up survey and administrative data.

The follow-up survey includes questions to confirm whether the respondent actually participated in the program. This is important because the COS enjoyed some degree of control over who took the course that is not reflected on the PCU administrative data. Also, in the process of replacing no-shows and dropouts some members of the $\mathrm{Zi}=$ 0 group were contacted as replacements and, even if some of them may have declined to participate, they are still classified as control group compliers.

During the follow-up survey, enumerators did not have information on the classification of the youth into the treatment or control groups according to the administrative data. Young people were asked if the COS contacted them after the registration to notify them that they had been selected and to inform them the date and time when the course would start. Table 4 presents the answers to this question, showing that a large fraction of those who were not selected in the lottery were contacted by the COS in order to participate in the program ${ }^{18}$.

Table 5 further explores the composition of the realized treatment and control groups according to administrative data and information from the follow-up survey.

According to administrative records, about 22 percent of the randomly assigned control group $\left(Z_{i}=0\right)$ and 85 percent of the treatment group $\left(Z_{i}=1\right)$ were contacted by the COS and accepted the course. Nonetheless, according to the follow-up survey, 37 percent of those not selected by the lottery $\left(Z_{i}=0\right)$ reported being contacted by the COS and accepting to participate in the program. Moreover, 23 percent of the control group $\left(Z_{i}=0\right)$ reported having taken the course and even completing an internship of three or more weeks. These figures show that compliance was low (in particular for the $Z i=0$ group). The lottery, however, did have a strong impact on the probability of participating and thus constitutes a very strong instrument ${ }^{19}$.

In this paper, the Di variable is defined based on information from the follow-up survey $^{20}$. Individuals for whom $\mathrm{Di}=1$ are those who reported having been contacted by the COS to begin the course and having accepted to start $i t^{21}$. Alternative measures of $\mathrm{Di}=1$ were also used in order to determine if there were any differences between those who started the program, those who completed the classroom training, and those who

Table 5 Final composition of the treatment and control groups

\begin{tabular}{|c|c|c|c|c|c|c|c|}
\hline & & \multicolumn{2}{|c|}{ Administrative data } & \multicolumn{2}{|c|}{$\begin{array}{l}\text { Follow-up survey: } \\
\text { accepted the course }\end{array}$} & \multicolumn{2}{|c|}{$\begin{array}{l}\text { Follow-up survey: completed course } \\
\text { and internship }\end{array}$} \\
\hline & & $Z i=0$ & $Z i=1$ & $Z i=0$ & $Z i=1$ & $Z i=0$ & $Z i=1$ \\
\hline \multirow[t]{2}{*}{$D_{i}$} & 0 & 1,098 & 389 & 883 & 380 & 1,088 & 799 \\
\hline & 1 & 309 & 2,240 & 524 & 2,249 & 319 & 1,830 \\
\hline \multicolumn{2}{|c|}{ TOTAL } & 1,407 & 2,629 & 1,407 & 2,629 & 1,407 & 2,629 \\
\hline
\end{tabular}

Source: Follow-up survey and administrative data. 
also completed the internship ${ }^{22}$. The analyses using alternative definitions of Di are robust.

\section{Results}

The outcomes explored in this paper can be classified into the following three categories:

- Labor market outcomes

- Outcomes related to youth behavior and life style, perceptions and expectations

- Measurements of socio-emotional skills.

We estimate the impact of the program on all of these outcomes for the complete sample and for various subgroups defined by gender, age, education, region and course $^{23}$. In addition, in order to interpret the results, we look at the relationship between the non-cognitive measures and labor market outcomes.

\subsection{Labor market outcomes}

Selected labor market outcomes in the follow-up survey by random assignment status are presented in Tables 6 and 7. In terms of employment rate, Table 6 shows that there are only minor differences between $\mathrm{Zi}=0$ and $\mathrm{Zi}=1$ : employment is 62.5 and 61.6 percent respectively.

Table 6 Employment characteristics in the follow-up survey

\begin{tabular}{|c|c|c|}
\hline Outcome & $Z_{i}=0$ & $Z_{i}=1$ \\
\hline Employed & $62.5 \%$ & $61.6 \%$ \\
\hline Agriculture and mining & $1.95 \%$ & $1.49 \%$ \\
\hline Industry & $9.60 \%$ & $8.29 \%$ \\
\hline Services & $88.5 \%$ & $90.2 \%$ \\
\hline Duration of current job (months) & 16.21 & 15.48 \\
\hline Permanent Job & $42.2 \%$ & $41.7 \%$ \\
\hline Employed at large firms ${ }^{a}$ & $12.7 \%$ & $13.2 \%$ \\
\hline Salaried workers & $35.2 \%$ & $36.4 \%$ \\
\hline Unpaid workers & $2.92 \%$ & $2.75 \%$ \\
\hline Self-employed workers & $20.8 \%$ & $19.5 \%$ \\
\hline Workers w/ labor risk insurance & $9.97 \%$ & $11.08 \%$ \\
\hline Workers with health insurance & $17.4 \%$ & $18.0 \%$ \\
\hline Workers with written contract & $12.7 \%$ & $13.8 \%$ \\
\hline Weekly worked days & 5.12 & 5.08 \\
\hline Weekly worked hours & 38.83 & 38.25 \\
\hline Wants to work more hours & $43.4 \%$ & $42.9 \%$ \\
\hline Wants to change current job & $50.4 \%$ & $48.9 \%$ \\
\hline Workers seeking another job & $17.7 \%$ & $19.1 \%$ \\
\hline Monthly wage (Dominican peso) ${ }^{b}$ & 2464.1 & 2535.5 \\
\hline Hourly wage (Dominican peso) ${ }^{b}$ & 18.38 & 18.26 \\
\hline
\end{tabular}

Source: Follow-up survey.

Note: Outcomes are unconditional on employment status.

a Large firms are those that employ 51 or more employees.

${ }^{\mathrm{b}}$ One US dollar $=35$ Dominican pesos. 
Table 7 Labor force participation status in the follow-up survey

\begin{tabular}{llr}
\hline Outcome & $\boldsymbol{Z}_{\boldsymbol{i}}=\mathbf{0}$ & $\boldsymbol{Z}_{\boldsymbol{i}}=\mathbf{1}$ \\
\hline All & & \\
Employed & $62.2 \%$ & $61.7 \%$ \\
Unemployed & $21.2 \%$ & $23.4 \%$ \\
Inactive & $16.6 \%$ & $14.9 \%$ \\
Male & & \\
Employed & $80.2 \%$ & $76.6 \%$ \\
Unemployed & $15.0 \%$ & $18.5 \%$ \\
Inactive & $4.9 \%$ & $4.8 \%$ \\
Female & & \\
Employed & $51.0 \%$ & $53.1 \%$ \\
Unemployed & $25.0 \%$ & $26.2 \%$ \\
Inactive & $24.0 \%$ & $20.7 \%$ \\
\hline Source: Follow-up survey. & &
\end{tabular}

Labor force participation is examined in Table 7. Female inactivity is larger for individuals assigned to the control group, while the opposite is true for employment and unemployment. Male inactivity and employment are higher for individuals assigned to the control group, while unemployment is higher for individuals assigned to the treatment group.

Figures 1 and 2 below show the employment history of individuals assigned to the treatment and control groups in the overall sample and in Santo Domingo. Taking into account the findings from the previous evaluation, program operators expected to find larger impacts in Santo Domingo because of its labor market dynamics. As expected, there were no differences in the months before the program started, particularly in the two to three months before registration took place. There were negative differences while trainees were taking the courses, and there was a catch-up after the courses. Overall, there were no impacts on employment, and in Santo Domingo there seems to be a positive difference in the months closer to the follow-up survey.

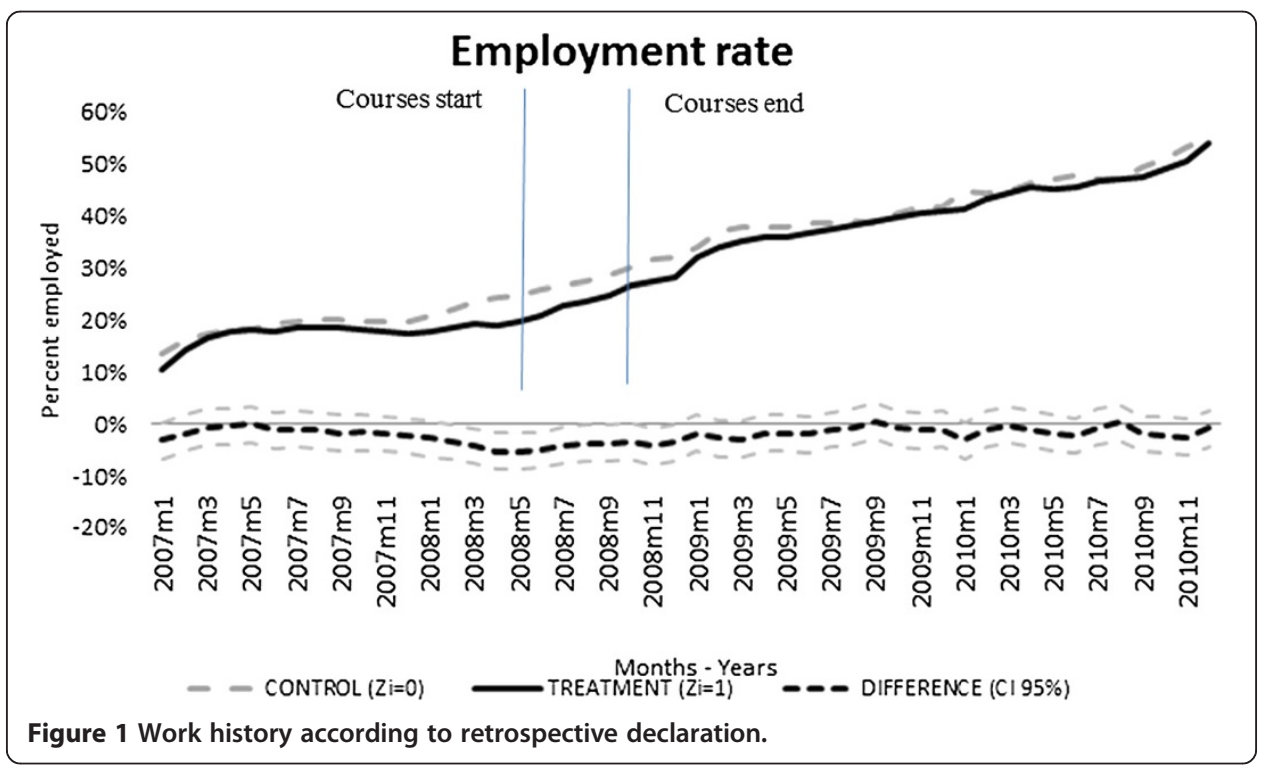




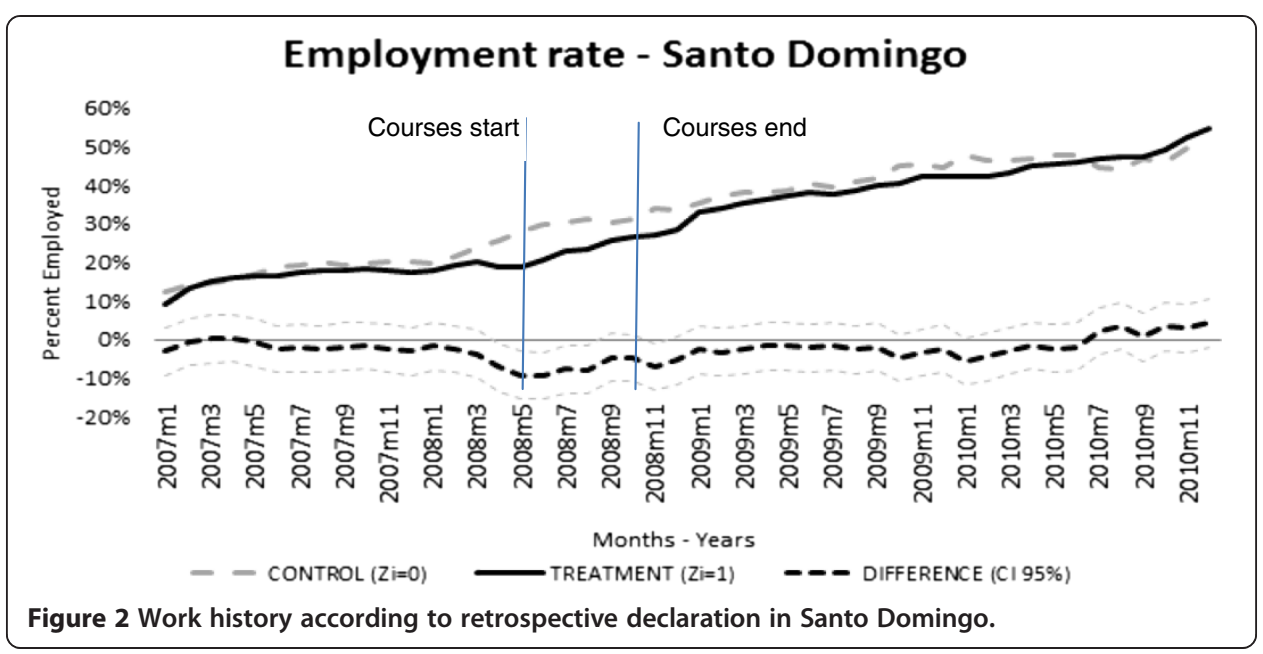

Table 8 shows the ITT estimates for the standard labor market outcomes. Although the program has no statistically significant impact on employment, for men it has statistically significant impacts on formality, measured as employer provided health insurance or as having a written contract. Males assigned to the treatment group are four percentage points more likely to get a job in the formal sector than males assigned to the control group. This represents an impact of 17 percent over the control group average $^{24}$. As shown in the last column, the results are particularly strong for males in Santo Domingo.

There is no impact on monthly earnings for the complete sample. However estimates for monthly earnings conditional on being employed show that the program does have a positive statistically significant impact. Among those employed, individuals assigned to the treatment group have monthly earnings seven percent higher than individuals assigned to the control group. This holds for women in general, and for men in Santo Domingo.

There also seems to be a relation with the duration of unemployment, which is longer for males assigned to the treatment group than for males assigned to the control group. This could reflect the fact that males assigned to the treatment group are searching for better quality jobs even if these are harder to find, or that they have higher reservation wages. This would also be consistent with the last result reported in the table: hours seeking for a job in the last working day. Here, the average time reported by individuals assigned to the treatment group reflects a 60 percent increase compared to the control group mean.

\subsection{Risky behavior and pregnancy, perceptions and expectations}

An important element of the life skills component is to enable young people to plan and think about their future in a more serious and organized manner. By giving them elements to increase their self-esteem and develop their personal abilities to compete in the labor market, young people can become more optimistic about their future and realize the importance of making the adequate decisions today, which may influence their risky behaviors. Hence, a first step in the success of the life skills component is raising young people's expectations about their future, as this should encourage them to engage in positive behaviors (which become more "profitable") and prevent them from undertaking negative ones (which become more "costly"). 
Table 8 ITT estimation on selected labor market outcomes

\begin{tabular}{|c|c|c|c|c|c|c|}
\hline Intention to treat effect & (1) & $(2)$ & (3) & (1) & (1) & $(2)$ \\
\hline Outcomes & All & Women & Men & $\begin{array}{l}\text { Santo } \\
\text { Domingo }\end{array}$ & SD women & SD men \\
\hline \multirow[t]{2}{*}{ Employed } & -0.0127 & 0.0069 & -0.0244 & 0.0035 & 0.0317 & -0.0285 \\
\hline & $(0.0178)$ & $(0.0237)$ & $(0.0234)$ & $(0.0334)$ & $(0.0436)$ & $(0.0418)$ \\
\hline $\mathrm{Zi}=0$ Mean & 0.625 & 0.516 & 0.797 & 0.599 & 0.519 & 0.752 \\
\hline \multirow[t]{2}{*}{ Employed with health insurance } & 0.0124 & 0.0024 & $0.0423^{*}$ & 0.0244 & -0.0048 & $0.1079^{* *}$ \\
\hline & $(0.0127)$ & $(0.0147)$ & $(0.0235)$ & $(0.0209)$ & $(0.0253)$ & $(0.0411)$ \\
\hline $\mathrm{Zi}=0$ Mean & 0.169 & 0.128 & 0.235 & 0.166 & 0.146 & 0.206 \\
\hline \multirow[t]{2}{*}{ Employed with written contract } & $0.0183^{*}$ & 0.0111 & $0.0430^{* *}$ & 0.0161 & -0.0063 & $0.0893^{* *}$ \\
\hline & $(0.0107)$ & $(0.0128)$ & $(0.0203)$ & $(0.0189)$ & $(0.0246)$ & $(0.0358)$ \\
\hline $\mathrm{Zi}=0$ Mean & 0.123 & 0.0924 & 0.171 & 0.127 & 0.108 & 0.163 \\
\hline \multirow[t]{2}{*}{ Monthly earnings } & 192.5509 & 249.2847 & 284.2723 & 393.8667 & 380.8441 & 591.6433 \\
\hline & $(170.2102)$ & (163.3309) & $(298.4813)$ & (358.8349) & (325.2659) & $(652.0422)$ \\
\hline $\mathrm{Zi}=0$ Mean & 2946 & 1932 & 4558 & 3074 & 2309 & 4527 \\
\hline \multirow[t]{2}{*}{ Ln monthly earnings } & $0.0866^{* *}$ & $0.1425^{* *}$ & 0.0931 & $0.1682^{* *}$ & 0.1605 & $0.2190^{*}$ \\
\hline & $(0.0436)$ & $(0.0644)$ & $(0.0586)$ & $(0.0736)$ & $(0.1085)$ & $(0.1185)$ \\
\hline $\mathrm{Zi}=0$ Mean & 8.223 & 7.999 & 8.441 & 8.306 & 8.167 & 8.479 \\
\hline \multirow[t]{2}{*}{ Labor force participation } & 0.0109 & 0.0153 & 0.0136 & 0.0143 & 0.0191 & 0.0165 \\
\hline & $(0.0128)$ & $(0.0192)$ & $(0.0129)$ & $(0.0222)$ & $(0.0321)$ & $(0.0256)$ \\
\hline $\mathrm{Zi}=0$ Mean & 0.837 & 0.771 & 0.942 & 0.846 & 0.799 & 0.936 \\
\hline \multirow{2}{*}{$\begin{array}{l}\text { Duration (weeks) of } \\
\text { unemployment }\end{array}$} & $2.6994^{* *}$ & 2.0906 & $3.4542^{* *}$ & 0.7825 & 1.4161 & -0.9038 \\
\hline & $(1.1297)$ & $(1.5952)$ & $(1.5079)$ & (2.0976) & $(2.8280)$ & (2.5909) \\
\hline $\mathrm{Zi}=0$ Mean & 8.883 & 11.24 & 5.143 & 11.75 & 12.98 & 9.402 \\
\hline \multirow{2}{*}{$\begin{array}{l}\text { Hours job-seeking in last } \\
\text { working day }\end{array}$} & $0.0620^{* *}$ & 0.0475 & $0.0901^{* *}$ & $0.1035^{* *}$ & $0.1100^{* *}$ & 0.1175 \\
\hline & $(0.0247)$ & $(0.0293)$ & $(0.0448)$ & $(0.0484)$ & $(0.0459)$ & $(0.1068)$ \\
\hline $\mathrm{Zi}=0$ Mean & 0.104 & 0.0944 & 0.119 & 0.113 & 0.0794 & 0.177 \\
\hline Observations & 3,761 & 2,350 & 1,411 & 1,197 & 797 & 400 \\
\hline
\end{tabular}

Note: Robust standard errors clustered at the course level in parentheses. COS fixed effects included in the estimation. ${ }^{* * *} \mathrm{p}<0.01,{ }^{* *} \mathrm{p}<0.05,{ }^{*} \mathrm{p}<0.1$.

One US dollar $=35$ Dominican pesos.

Table 9 presents, for all females in the sample regardless of their marital status, the impact of the program on pregnancy at the time of the follow-up survey. The estimates indicate that the program had a statistically significant negative impact on the probability of being pregnant. Females in the treatment group were on average two percentage points less likely to be pregnant than females in the control group. It is worth noting that this effect was driven by the group of females between 16 and 19 years old. Hence, the program was effective in reducing teenage pregnancy, which as discussed in the introduction is related to their future labor market outcomes. ITT estimates for other risky behaviors such as consumption of alcohol, cigarettes, drugs and lottery were also computed. However, while the individuals assigned to the treatment group seemed to spend on average less money on consumption of these goods than the individuals assigned to the control group, the differences were not statistically significant. 
Table 9 ITT estimation on pregnancy

\begin{tabular}{lllllll}
\hline $\begin{array}{l}\text { Intention to treat effect } \\
\text { Outcomes }\end{array}$ & $\begin{array}{l}\mathbf{( 1 )} \\
\text { All women }\end{array}$ & $\begin{array}{l}\text { (2) } \\
\text { Age 16-19 }\end{array}$ & $\begin{array}{l}\text { (3) } \\
\text { Age 20-24 }\end{array}$ & $\begin{array}{l}\text { (4) } \\
\text { Age }>\text { 24 } 4\end{array}$ & $\begin{array}{l}\text { (5) } \\
\text { Incomplete } \\
\text { elementary }\end{array}$ & $\begin{array}{l}\text { Incomplete } \\
\text { high school }\end{array}$ \\
\hline Pregnant & $-0.0226^{* *}$ & $-0.0492^{*}$ & -0.0157 & 0.0053 & -0.0478 & -0.0195 \\
& $(0.0110)$ & $(0.0292)$ & $(0.0182)$ & $(0.0160)$ & $(0.0298)$ & $(0.0147)$ \\
Zi = 0 Mean & 0.0810 & 0.115 & 0.0811 & 0.0472 & 0.118 & 0.0785 \\
Observations & 2,350 & 599 & 1,098 & 653 & 467 & 1,331 \\
\hline
\end{tabular}

Note: Robust standard errors clustered at the course level in parentheses. COS fixed effects included in the estimation. ${ }^{* * *} \mathrm{p}<0.01,{ }^{* *} \mathrm{p}<0.05,{ }^{*} \mathrm{p}<0.1$.

Results for perceptions and expectations are presented in Table 10. The project has a positive impact in improving youth perceptions about their current situation and their expectations regarding the future ${ }^{25}$. On average, individuals assigned to the treatment group are more likely to consider having a very good health than those in the control group, and are more likely to have higher expectations about their future in topics related to their education level, neighborhood, owning a business, having the desired job, completing professional aspirations, having a better life in 20 years, offering their children a better life, and having a wealthier position and more social recognition in 10 years $^{26}$. These impacts are stronger for females and younger individuals. In other words, it is women and adolescents that seem to get more optimistic when assigned to the program. Estimates for expectations of negative situations such as getting HIVAIDS, dying violently or being involved in criminal activities were also estimated. However, there was no statistically significant impact on expectations related to negative situations. This may be consistent with training increasing the optimism and overconfidence bias (Thaler and Sunstein 2009) by overstating the likelihood of positive outcomes in the future. Not observing changes in the estimation of negative outcomes is consistent with the fact that training emphasized positive emotional skills (and not so much the costs and dangers of risky behavior), and also that people do not like to think of themselves in negative situations.

Raising expectations is valuable not only as a channel to discourage negative (risky, unproductive) behaviors and results, but as a channel to encourage positive (healthy, productive) ones. In this regard, the observed increase in positive expectations may not only be related to the observed changes in risky behaviors, in this case, particularly, to teenage pregnancy, but also to the observed increase in productive behaviors, such as those related to entering the labor market. As shown in the previous section, individuals in the treatment group on average devote more time to search for a job than individuals in the control group. They also tend to remain unemployed longer before finding a job, perhaps because they are more demanding in terms of job quality and reservation wages. Thus, these results could be related to their more positive perceptions of themselves and optimistic expectations about the future.

In fact, this is the whole point about changing youth expectations: to trigger desirable behavioral changes that may lead to better socio-economic results, including labor market ones. To the extent that raising positive perceptions and expectations translates into healthier and more productive behaviors, which in turn lead to better social and employment conditions, there is a reason for encouraging such changes in youth. On 
Table 10 ITT estimation on expectations

\begin{tabular}{|c|c|c|c|c|c|c|}
\hline Intention to treat effect & (1) & (2) & (3) & (4) & (5) & (6) \\
\hline Outcomes & All & Women & Men & Age 16-19 & Age $20-24$ & Age $>24$ \\
\hline \multirow[t]{2}{*}{ Considers having very good health (\%) } & $0.0386^{* *}$ & $0.0382^{* *}$ & $0.0533^{*}$ & 0.0321 & $0.0646^{* * *}$ & 0.0085 \\
\hline & $(0.0151)$ & $(0.0181)$ & $(0.0272)$ & $(0.0291)$ & $(0.0245)$ & $(0.0288)$ \\
\hline $\mathrm{Zi}=0$ Mean & 0.287 & 0.222 & 0.392 & 0.315 & 0.291 & 0.244 \\
\hline \multirow{2}{*}{$\begin{array}{l}\text { Expectations: Having a better } \\
\text { education level }\end{array}$} & $0.0577^{*}$ & $0.1021^{* * *}$ & -0.0023 & $0.1063^{*}$ & $0.0809^{*}$ & -0.0441 \\
\hline & $(0.0299)$ & $(0.0389)$ & $(0.0444)$ & $(0.0558)$ & $(0.0427)$ & $(0.0646)$ \\
\hline $\mathrm{Zi}=0$ Mean & 4.180 & 4.175 & 4.189 & 4.236 & 4.143 & 4.186 \\
\hline \multirow{2}{*}{$\begin{array}{l}\text { Expectations: Living in a better } \\
\text { neighborhood }\end{array}$} & 0.0477 & $0.1077^{* *}$ & -0.0515 & $0.1045^{*}$ & 0.0359 & 0.0582 \\
\hline & $(0.0330)$ & $(0.0426)$ & $(0.0523)$ & $(0.0619)$ & $(0.0475)$ & $(0.0760)$ \\
\hline $\mathrm{Zi}=0$ Mean & 3.898 & 3.886 & 3.918 & 3.840 & 3.932 & 3.904 \\
\hline \multirow[t]{2}{*}{ Expectations: Owning a business } & 0.0553 & $0.0968^{* *}$ & -0.0085 & $0.1699^{* *}$ & 0.0271 & 0.0295 \\
\hline & $(0.0384)$ & $(0.0483)$ & $(0.0637)$ & $(0.0832)$ & $(0.0541)$ & $(0.0781)$ \\
\hline $\mathrm{Zi}=0$ Mean & 3.759 & 3.728 & 3.809 & 3.609 & 3.813 & 3.842 \\
\hline \multirow{2}{*}{$\begin{array}{l}\text { Expectations: Completing } \\
\text { professional aspirations }\end{array}$} & $0.0684^{* *}$ & $0.0911^{* * *}$ & 0.0353 & $0.1543^{* * *}$ & 0.0582 & -0.0163 \\
\hline & $(0.0276)$ & $(0.0331)$ & $(0.0461)$ & $(0.0513)$ & $(0.0410)$ & $(0.0601)$ \\
\hline $\mathrm{Zi}=0$ Mean & 4.250 & 4.262 & 4.231 & 4.199 & 4.267 & 4.282 \\
\hline \multirow{2}{*}{$\begin{array}{l}\text { Expectations: Having a better } \\
\text { life in } 20 \text { years }\end{array}$} & $0.0543^{* *}$ & $0.0590^{*}$ & 0.0565 & $0.1811^{* * *}$ & 0.0057 & 0.0230 \\
\hline & $(0.0249)$ & $(0.0317)$ & $(0.0419)$ & $(0.0518)$ & $(0.0316)$ & $(0.0573)$ \\
\hline $\mathrm{Zi}=0$ Mean & 4.455 & 4.471 & 4.429 & 4.386 & 4.502 & 4.443 \\
\hline \multirow{2}{*}{$\begin{array}{l}\text { Expectations: Children having } \\
\text { a better life }\end{array}$} & 0.0360 & 0.0426 & 0.0124 & $0.1224^{* *}$ & -0.0017 & 0.0387 \\
\hline & $(0.0238)$ & $(0.0298)$ & $(0.0396)$ & $(0.0481)$ & $(0.0338)$ & $(0.0487)$ \\
\hline $\mathrm{Zi}=0$ Mean & 4.523 & 4.544 & 4.489 & 4.472 & 4.543 & 4.546 \\
\hline \multirow{2}{*}{$\begin{array}{l}\text { Expectations: Wealth position } \\
\text { in } 10 \text { years }\end{array}$} & $0.0677^{* *}$ & $0.1057^{* * *}$ & 0.0049 & 0.0731 & 0.0272 & $0.1742^{* * *}$ \\
\hline & $(0.0278)$ & $(0.0353)$ & $(0.0472)$ & $(0.0532)$ & $(0.0392)$ & $(0.0633)$ \\
\hline $\mathrm{Zi}=0$ Mean & 3.932 & 3.943 & 3.915 & 3.950 & 3.974 & 3.821 \\
\hline Observations & 3,761 & 2,350 & 1,411 & 1,068 & 1,814 & 879 \\
\hline
\end{tabular}

Note: Robust standard errors clustered at the course level in parentheses.

COS fixed effects included in the estimation.

${ }^{* * *} p<0.01,{ }^{* *} p<0.05,{ }^{*} p<0.1$.

Expectations are measured in a 1 (very unlikely) to 5 (very likely) scale.

the contrary, if none of the latter does happen, then there would not be a point for increasing expectation per se, at least from a labor market insertion perspective ${ }^{27}$.

\subsection{Life skills}

A contribution of this paper is to present empirical evidence on the impacts of training on life skills. For this purpose, the Social and Personal Competencies Scale, CPS for its Spanish acronym (Escala de Competencias Personales y Sociales) was developed in July 2010 by a team of experts to evaluate the life skills component of the program. The CPS is a non-cognitive test that measures the effectiveness of the life skills module of the program in developing positive attitudes and values. The test measures six basic competencies: leadership, behavior in situations of conflict, self-esteem, abilities to 
relate with others, order, and empathy and communication skills. It produces a general score and a specific score for each of these dimensions. A higher score in the scale is associated with a higher level of development in the social and personal competencies.

We also use the Rosenberg and Grit scales, which are standard and proven methodologies in psychology to measure personality traits and socio-emotional competence. The Rosenberg Scale is a professional instrument used in clinical practice to measure self-esteem levels ${ }^{28}$. The test is composed of 10 questions that should take between one to three minutes to answer. A higher score on the scale is associated with a higher level of self-esteem (Brea 2010). The Grit Scale focuses on determination and strength of mind $^{29}$. It measures persistency of effort, enthusiasm about long term goals, consistency of interests, and ambition. The instrument consists of 13 questions that can be completed in one to four minutes. Higher scores on the Grit Scale are associated with higher levels of determination and motivation during long periods of time despite failure or adversity (Brea 2010).

Scores for our sample were all estimated as described in Brea (2010). Results are presented in terms of standard deviations in order to ease interpretation. As shown in Table 11, the program has a positive and statistically significant impact in most

Table 11 ITT estimation on the CPS scale

\begin{tabular}{|c|c|c|c|c|c|c|}
\hline Intention to treat effect & (1) & (2) & (3) & (4) & (5) & (6) \\
\hline Outcomes $((\mathrm{Xi}-\mathrm{Xc}) / \sigma c)$ & All & Women & Men & Age 16-19 & $\begin{array}{l}\text { Incomplete } \\
\text { high school }\end{array}$ & $\begin{array}{l}\text { Santo } \\
\text { Domingo }\end{array}$ \\
\hline \multirow[t]{2}{*}{ Total CPS Score } & $0.1025^{* * *}$ & $0.0888^{* *}$ & $0.1364^{* *}$ & $0.1960^{* * *}$ & $0.1095^{* *}$ & $0.2584^{* * *}$ \\
\hline & $(0.0364)$ & $(0.0442)$ & $(0.0670)$ & $(0.0636)$ & $(0.0465)$ & $(0.0609)$ \\
\hline \multirow[t]{2}{*}{ CPS: Leadership } & $0.0862^{* *}$ & 0.0552 & $0.1425^{* *}$ & $0.1585^{* *}$ & 0.0751 & $0.1651^{* * *}$ \\
\hline & $(0.0357)$ & $(0.0441)$ & $(0.0607)$ & $(0.0637)$ & $(0.0464)$ & $(0.0617)$ \\
\hline \multirow[t]{2}{*}{ CPS: Behavior in situations of conflict } & $0.1049^{* * *}$ & $0.1017^{* *}$ & $0.1128^{*}$ & $0.2414^{* * *}$ & $0.1023^{* *}$ & $0.2693^{* * *}$ \\
\hline & $(0.0368)$ & $(0.0461)$ & $(0.0643)$ & $(0.0670)$ & $(0.0478)$ & $(0.0639)$ \\
\hline \multirow[t]{2}{*}{ CPS: Self-esteem } & $0.0719^{* *}$ & 0.0444 & $0.1265^{* *}$ & $0.1590^{* *}$ & 0.0542 & $0.1612^{* *}$ \\
\hline & $(0.0358)$ & $(0.0449)$ & $(0.0612)$ & $(0.0650)$ & $(0.0442)$ & $(0.0640)$ \\
\hline \multirow[t]{2}{*}{ CPS: Abilities to relate with others } & 0.0510 & 0.0459 & 0.0579 & $0.1133^{*}$ & 0.0309 & $0.1633^{* *}$ \\
\hline & $(0.0369)$ & $(0.0457)$ & $(0.0633)$ & $(0.0647)$ & $(0.0455)$ & $(0.0644)$ \\
\hline \multirow[t]{2}{*}{ CPS: Empathy and communication skills } & 0.0525 & 0.0533 & 0.0768 & 0.0588 & $0.1169^{* * *}$ & $0.1558^{* * *}$ \\
\hline & $(0.0337)$ & $(0.0433)$ & $(0.0613)$ & $(0.0644)$ & $(0.0450)$ & $(0.0543)$ \\
\hline \multirow[t]{2}{*}{ CPS: Order and self-organization } & $0.0966^{* * *}$ & $0.0875^{* *}$ & $0.1124^{*}$ & $0.1758^{* * *}$ & 0.0702 & $0.2412^{* * *}$ \\
\hline & $(0.0354)$ & $(0.0424)$ & $(0.0606)$ & $(0.0595)$ & $(0.0441)$ & $(0.0607)$ \\
\hline \multirow[t]{2}{*}{ Rosenberg's Scale } & 0.0183 & -0.0417 & $0.1087^{*}$ & 0.0734 & 0.0637 & 0.0083 \\
\hline & $(0.0364)$ & $(0.0439)$ & $(0.0608)$ & $(0.0667)$ & $(0.0462)$ & $(0.0629)$ \\
\hline \multirow[t]{2}{*}{ Total Grit Scale } & $0.0750^{* *}$ & $0.1019^{* *}$ & 0.0208 & $0.1451^{* *}$ & $0.1042^{* *}$ & $0.1133^{* *}$ \\
\hline & $(0.0373)$ & $(0.0446)$ & $(0.0642)$ & $(0.0661)$ & $(0.0476)$ & $(0.0560)$ \\
\hline \multirow[t]{2}{*}{ Grit: Persistency of effort } & $0.0757^{* *}$ & $0.0996^{* *}$ & 0.0209 & $0.1837^{* * *}$ & $0.1202^{* * *}$ & $0.1357^{* *}$ \\
\hline & $(0.0355)$ & $(0.0421)$ & $(0.0622)$ & $(0.0644)$ & $(0.0434)$ & $(0.0578)$ \\
\hline \multirow[t]{2}{*}{ Grit: Ambition } & $0.0686^{*}$ & $0.0791^{*}$ & 0.0241 & $0.1611^{* *}$ & $0.1224^{* * *}$ & 0.0878 \\
\hline & $(0.0351)$ & $(0.0428)$ & $(0.0642)$ & $(0.0623)$ & $(0.0430)$ & $(0.0591)$ \\
\hline Observations & 3,761 & 2,350 & 1,411 & 1,068 & 2,129 & 1,197 \\
\hline
\end{tabular}

Note: Robust standard errors clustered at the course level in parentheses. COS fixed effects included in the estimation. ${ }^{* * *} p<0.01,{ }^{* *} p<0.05,{ }^{*} p<0.1$. 
CPS measures. On average, the total CPS score of individuals assigned to the treatment group is 0.11 standard deviations higher than the score of individuals assigned to the control group. Impacts of similar magnitudes hold for CPS scores on leadership, behavior in situations of conflict, self-esteem, and order and self-organization. There are no overall impacts on the CPS scores on abilities to relate with others and empathy and communication skills. For most of the indicators these results hold for both males and females, but the impact on males tends to be larger. By groups, the impact concentrates on the youngest individuals, on the better educated -incomplete high school is the highest education level to be eligible for the program- and in Santo Domingo. While the program does not have an impact on the Rosenberg Scale for the complete sample, it increases the Rosenberg Scale of males in about 0.11 standard deviations. Looking at the impacts on the Grit Scale, the estimates show that the program has a positive and statistically significant effect in the total scale and in the sub-scales for persistency of effort and ambition. On average, the total Grit Scale of individuals assigned to the treatment group is 0.08 standard deviations higher than the score of individuals assigned to the control group. The impact on the subscales mentioned above is comparable in magnitude. As in the results for the CPS scale, impacts on the total Grit Scale and the different subscales concentrate and are stronger on the youngest individuals, the ones with higher educational attainment, and on those living in Santo Domingo. However, there is a sharp contrast on the results by gender, as in this case the impacts are only statistically significant for females.

While there is a statistically significant impact on several of the measures of noncognitive development analyzed above, it is hard to determine the practical significance of these results. Literature on the relationship between non-cognitive skills and professional success is relatively new and it is still uncertain which specific competencies positively relate to participation in the labor market. In addition, there is also little evidence on the magnitude of the changes in non-cognitive abilities that are required to generate observable changes on the levels of youth employability.

However, in the literature on cognitive and non-cognitive skills development there is some indication that our results are moving on the desired direction. While the existing studies are not directly comparable to ours as they analyze different populations and interventions, they at least give us an idea of the potential of the program in terms of the magnitude of the effects measured in standard deviations. Evidence on the development of cognitive skills is largely available in the education sector literature. In general, successful interventions in primary education have an impact of close to 0.4 standard deviations per year in educational attainment ${ }^{30}$. Evidence on the development of non-cognitive skills is much more limited, but a recent study by Felfe et al. (2011) shows that participation in sports clubs by children aged three to 10 years old in Germany has an overall positive impact of 0.13 standard deviations in non-cognitive skills. Therefore, taking into account that the life skills component of the program only lasted 75 hours and had impacts of around 0.1 standard deviations in several measures of non-cognitive development 18-24 months after the end of the courses, it seems to be the case that the effect of the program on noncognitive abilities is sizable ${ }^{31}$. 
Given that there is a robust statistically significant impact of the program on noncognitive skills as measured by three different instruments, and taking into account that there is only limited empirical evidence on the role of non-cognitive development and labor market outcomes, we carried out an exercise to further explore the relation between each of the scales used in this paper to measure life skills and the probability of being employed. We estimate standard regressions in which the dependent variable is the employment status of the individual and the explanatory variable of interest is each of the above scales for the control group ${ }^{32}$. The regressions include a set of additional covariates to control for gender, age, education, experience, and whether the individual is currently attending school. Table 12 presents the results from this exercise which are rather disappointing: there does not seem to be any meaningful association between having higher levels of life skills, as measured by our instruments, and employment ${ }^{33,34}$.

\section{Conclusions}

Juventud $y$ Empleo is a labor training program for disadvantaged youth in the Dominican Republic. It is one of the first programs of its type in Latin America to

Table 12 OLS estimation on employment and the CPS scale (control group)

\begin{tabular}{|c|c|c|c|c|c|c|}
\hline OLS estimations & (1) & $(2)$ & (3) & (4) & (5) & (6) \\
\hline Dependent variable: employed & All & Women & Men & Age 16-19 & $\begin{array}{l}\text { Incomplete } \\
\text { high school }\end{array}$ & $\begin{array}{l}\text { Santo } \\
\text { Domingo }\end{array}$ \\
\hline \multirow[t]{2}{*}{ Total CPS Score } & 0.0076 & 0.0146 & -0.0052 & 0.0013 & 0.0049 & -0.0051 \\
\hline & $(0.0134)$ & $(0.0189)$ & $(0.0195)$ & $(0.0268)$ & $(0.0193)$ & $(0.0234)$ \\
\hline \multirow[t]{2}{*}{ CPS: Leadership } & -0.0044 & 0.0054 & -0.0266 & -0.0052 & -0.0073 & -0.0233 \\
\hline & $(0.0133)$ & $(0.0186)$ & $(0.0195)$ & $(0.0260)$ & $(0.0192)$ & $(0.0244)$ \\
\hline \multirow[t]{2}{*}{ CPS: Behavior in situations of conflict } & -0.0089 & -0.0170 & -0.0035 & -0.0185 & -0.0076 & -0.0322 \\
\hline & $(0.0134)$ & $(0.0189)$ & (0.0198) & $(0.0271)$ & $(0.0193)$ & $(0.0231)$ \\
\hline \multirow[t]{2}{*}{ CPS: Self-esteem } & 0.0172 & 0.0157 & 0.0245 & -0.0046 & 0.0247 & 0.0057 \\
\hline & $(0.0133)$ & $(0.0186)$ & $(0.0206)$ & $(0.0275)$ & $(0.0197)$ & $(0.0244)$ \\
\hline \multirow[t]{2}{*}{ CPS: Abilities to relate with others } & 0.0167 & 0.0181 & 0.0117 & 0.0240 & 0.0146 & 0.0131 \\
\hline & $(0.0137)$ & $(0.0189)$ & $(0.0209)$ & $(0.0276)$ & $(0.0198)$ & $(0.0237)$ \\
\hline \multirow[t]{2}{*}{ CPS: Order and self-organization } & 0.0066 & 0.0143 & -0.0103 & 0.0137 & 0.0109 & 0.0123 \\
\hline & $(0.0135)$ & $(0.0188)$ & $(0.0201)$ & $(0.0267)$ & $(0.0197)$ & $(0.0225)$ \\
\hline \multirow[t]{2}{*}{ Rosenberg's Scale } & 0.0069 & 0.0171 & -0.0046 & 0.0027 & 0.0160 & 0.0196 \\
\hline & $(0.0136)$ & $(0.0195)$ & $(0.0190)$ & $(0.0253)$ & $(0.0185)$ & $(0.0237)$ \\
\hline \multirow[t]{2}{*}{ Total Grit Scale } & 0.0046 & 0.0043 & 0.0040 & -0.0145 & -0.0223 & -0.0101 \\
\hline & $(0.0136)$ & $(0.0191)$ & $(0.0201)$ & $(0.0260)$ & $(0.0182)$ & $(0.0247)$ \\
\hline \multirow[t]{2}{*}{ Grit: Persistency of effort } & 0.0196 & 0.0256 & 0.0095 & -0.0003 & -0.0172 & -0.0020 \\
\hline & $(0.0137)$ & $(0.0190)$ & $(0.0207)$ & $(0.0261)$ & $(0.0185)$ & $(0.0248)$ \\
\hline \multirow[t]{2}{*}{ Grit: Ambition } & -0.0118 & -0.0112 & -0.0084 & $-0.0416^{*}$ & $-0.0406^{* *}$ & -0.0282 \\
\hline & $(0.0136)$ & $(0.0189)$ & $(0.0210)$ & $(0.0250)$ & $(0.0187)$ & $(0.0250)$ \\
\hline Mean dependent variable & 0.625 & 0.516 & 0.797 & 0.588 & 0.630 & 0.599 \\
\hline Observations & 1,286 & 790 & 496 & 381 & 717 & 409 \\
\hline
\end{tabular}

Note: Robust standard errors clustered at the course level in parentheses. COS fixed effects included in the estimation.

${ }^{* * *} p<0.01,{ }^{* *} p<0.05,{ }^{*} p<0.1$. 
incorporate a randomized design that allows the implementation of rigorous impact evaluations, which provide feedback to the program in its different phases. The first impact evaluation of JE showed limited impacts on employment and wages, which lead to changes in the program that focused on working closer with the private sector and providing a stronger life skills component, which were identified by employers as the most valuable component of the project. This evaluation looks at data from the first cohort since the program was re-launched, and evaluates the impact of the program both on traditional labor market outcomes and on outcomes related to youth behavior and life style, expectations about the future and socio-emotional skills.

While the design and implementation of this evaluation incorporated the lessons from the first JE evaluation experience, there were still certain flaws that could have been prevented and that should be taken into account in future evaluations of the JE program and other training programs. Mainly, the compliance with the randomization protocol should have been stricter and should have limited the possibilities for COS to include individuals from the control group in the program. A potential solution for this difficulty could have been randomizing the pool of eligible potential participants into three groups: treatment, control and waitlist. In this way, the COS would have only been allowed to contact individuals in the waitlist group, keeping the control group completely clean. This would have also contributed to making administrative data more transparent and likely more consistent with the follow up survey.

Despite the adverse economic conditions under which the cohort under study participated and graduated from JE, there are positive impacts on quality of employment for males. On average, males in the treatment group are four percentage points more likely to have employer provided health insurance than individuals in the control group. The program also has a positive effect on monthly earnings among those employed. On average, employed individuals in the treatment group have monthly earnings that are seven percent higher than employed individuals in the control group. Both of these results are even stronger for Santo Domingo, were the impacts reach 11 and 24 percentage points, respectively. The program, however, has no statistically significant impact on overall employment. Here, it should be noted that an important caveat of this type of evaluations is their partial equilibrium approach. While the evaluation can assert that the program has some positive impacts on the quality of the jobs that participants get, particularly men, it does not inform on whether these good jobs are incremental or if they correspond to crowding-out by program participants. Hence, it is possible that the positive impacts may be overstated ${ }^{35}$.

Regarding outcomes related to youth behavior, expectations and non-cognitive skills, the results from this evaluation are somewhat positive. The program is effective in reducing pregnancy, especially in teenagers. Females aged 16-19 in the treatment group are on average five percentage points less likely to be pregnant at the moment of the follow up survey. This corresponds to a 45 percent drop in comparison to the average pregnancy rate for the same age group in the control group.

The reduction in the pregnancy rate is consistent with the positive impact of the program in terms of youth expectations about their future, which could be leading to 
positive changes in youth behavior. On average, individuals in the treatment group, and especially females and younger individuals, have higher expectations about their future in terms of having a better life in 20 years, living in a better neighborhood, owning a business, and moving up in the wealth ladder.

This evaluation also shows positive impacts of JE in different measures of noncognitive skills. Using the CPS, Rosenberg and Grit scales, estimations show a consistent improvement in scores, ranging between 8 and 16 percent of a standard deviation. It is hard to interpret the practical significance of these results as evidence on this topic is very limited. Further analyses carried out in this paper show no correlation between some of these measures and employment. These results should encourage further research on the relationship between non-cognitive skills and labor market performance in order to understand the mechanisms through which life skills training can contribute to youth insertion into the labor market. Research on the instruments used to measure such skills is also needed.

Overall, is it worth spending scarce resources in this program (or in this type of programs)? The average cost of this program was about US $\$ 700$, of which US $\$ 200$ were transfers to participants as stipend for transportation and meals. Assuming no opportunity costs of participants during the training and if the impacts on income are maintained at $8 \%$, the cost -without transfers- would be recovered in about 50 months (the average income of the control group was about US\$130 $)^{36}$. We also documented impacts in reducing teenage pregnancy, which clearly has a positive value in terms of health and labor market perspectives of those youngsters. The program reduced one pregnancy for every twenty teenage female participants, so the cost of preventing one teenage pregnancy would be in the range of US\$10,000-US\$66,000 $0^{37}$. Also, if in the long run more non-cognitive skills and more positive expectations result in better labor market outcomes or life paths, the benefits would increase accordingly. However, in the short-run, these programs are clearly not a big win. But then again, development practitioners are well aware that big wins are extremely rare. In any case, while policymakers continue to face social pressure to deal with the ongoing problem of youth unemployment and program managers will claim that the newest version of the project will certainly yield positive results, it is necessary to continue evaluating and learning from the implementation of these projects.

\section{Endnotes}

${ }^{1}$ See Heckman et al. (1999) for a general overview of training programs, and Betcherman and Dar (2004) for a recent summary that includes some evaluations of developing country training programs.

${ }^{2}$ The Job Training Partnership Act program is described extensively by Heckman et al. (1999). Dolton, Makepeace and Treble (1994) describe the Youth Training Scheme.

${ }^{3}$ For a recent assessment of these programs, see Gonzalez et al. (2011).

${ }^{4}$ As implemented in LAC, these programs place a heavy emphasis on the private sector, both as a provider of training and as a demander of trainees. Private training firms compete for public funds with proposals that need to be backed by commitments from local employers to offer internships. 
${ }^{5}$ While cognitive skills are related to the ability to learn and the intellectual coefficient, socio-emotional or non-cognitive skills (also known as personality traits or life skills) are related to behaviors and attitudes, and are also referred to as to "soft skills".

${ }^{6}$ While interesting it is important to note that these findings must be interpreted cautiously, since the sub-sample of largest impact was determined after the fact, rather than based on an ex ante analysis plan.

${ }^{7}$ The study on Colombia reports a modest and statistically insignificant effect on overall employment (including unpaid work), but a large and statistically significant effect on formal sector employment.

${ }^{8}$ While the role of the private sector as driver of demand was envisioned since the design of the original program, in practice internships were provided without any real prospect of employment. This in part was due to the lag between the moment when training courses were developed by $\mathrm{COS}$ and private firms and the moment when graduates where actually ready for the internship, which was determined by how courses were selected, in term-specific public bids. In the new program, course selection would be done throughout the year, in order to respond better to private sector demand.

${ }^{9} \mathrm{~A}$ complementary evaluation based on another cohort of trainees led by the World Bank analyzed the impact of providing only life skills versus the traditional training, and their preliminary findings suggest that there is no valued added of the technical training (Martinez 2011). A qualitative analysis by Fazio (2011) presents additional evidence that firms value more the life skills component than the technical training.

${ }^{10}$ The eligibility criteria are that participants should be 16 to 29 years old; living in poor neighborhoods; not attending school; with incomplete high school or less; unemployed, underemployed or inactive; and hold an identity card.

${ }^{11}$ However, there are no reasons to believe that this imperfect compliance was due to defiers; that is, to individuals who did exactly the opposite of what was indicated to them by the lottery, regardless of its result. Given that program participants were selected from a pool of applicants who had registered voluntarily to participate in the course, it does not seem likely that some of these individuals would have declined the course when winning the lottery and managed to enter the course when losing it. Such situation would have been like having some individuals wanting to boycott the program, which to our knowledge never occurred. On the contrary, the program seemed to be positively accepted and perceived at the local and national level.

${ }^{12}$ See Angrist and Pischke (2009); and Duflo et al. (2008).

${ }^{13}$ If the program has a positive impact and we compare $\mathrm{Zi}=1$ with $\mathrm{Zi}=0$ but less than 100 percent of the former took the percent of the former took the course and more than 0 percent of the latter participated in the program, then the comparison yields an underestimation of the "true" program impacts. This is why under imperfect compliance of the random assignment the ITT leads to the dilution of the impact of the program.

${ }^{14}$ Although we can estimate the size of the compliers (as the difference in the participation rate among those that won and those that lost the lottery), we cannot 
identify them individually. The impact on this group is known as the Local Average Treatment Effect (LATE), which yields a larger impact than the ITT since it assumes that any difference in the average outcome between the $\mathrm{Zi}=1$ group and the $\mathrm{Zi}=0$ group is due to the larger fraction of the former that participated in the training. Thus, the estimation of the LATE for JE compliers yields the impact of the program on those who were treated because they won the lottery; otherwise they would not have been recruited to attend the courses. In the instrumental variables jargon, the lottery is an instrument, unrelated with the outcome but related to participation in the program (it increases the probability of participation by about fifty percentage points).

${ }^{15}$ We also estimate the LATE using Two Stage Least Squares (2SLS): the estimates are simply the OLS reduced form scaled up by the difference in the participation rate between those with $\mathrm{Zi}=1$ and $\mathrm{Zi}=0$ (the first stage of the 2SLS). Given that standard errors are adjusted accordingly, statistical significance does not change. Results for LATE estimations are shown in the Additional file 1.

${ }^{16}$ The sample size was set at 5,000 to detect an 8 percent increase in income with a power of 0.8 and an attrition of 30 percent of the sample with the sampsi Stata command.

${ }^{17}$ Most of the questions that measure labor market outcomes are based on the ENFT that is carried out twice a year by the Central Bank of the Dominican Republic. Some questions were modified and adapted to the JE evaluation and youth population; the basic indicators of labor force participation are generated following the ENFT and allow performing an external validation of our data.

${ }^{18}$ The fact that such a large fraction of the individuals with $Z i=0$ were contacted to begin the course is partly explained by the rule that allowed COS to contact up to 33 percent (5 out of 15) of controls as replacements for no-shows or dropouts. However, even after accounting for this, a proportion of 47 percent seems considerably large and reflects that non-compliance was high and that in practice COS were not rigorous in the application of the randomization protocol. While they did contact almost everyone that won the lottery, they also contacted nearly half of the people that didn't. Given that the decision about who in the control group to contact (apart from the 33\% for replacements) was probably not random, this noncompliance might have generated a bias in the selection of individuals into the program. For this reason, most of the analyses in this paper are based on ITT estimates.

${ }^{19}$ When looking at baseline characteristics among the different complier and non-complier groups there does not seem to be any statistically significant differences. Only the number of children seems to be statistically different (at a 10\% level) before the program between these groups, with the never-taker group having a larger amount of children on average. Additional file 1: Table S2 presents this information.

${ }^{20}$ Given that the follow-up survey shows a larger "always taker" group than the administrative data, it was decided to define Di based on the latter in order to be more conservative. Also, taking into consideration that COS may have had incentives to under report such group as it reveals their own non-compliance with the randomization protocol, the information from the follow-up survey was found to be more reliable. 
${ }^{21}$ Another filter was introduced. We wanted to make sure that those that were not contacted by the COS did not manage to participate in the program by other methods. Hence, we include in the $\mathrm{Di}=1$ group those that report having taken the course, despite the fact that they were never contacted to begin the courses. Approximately 30 individuals from the control group with these characteristics were accepted by the COS to take the course and complete the internship.

${ }^{22} \mathrm{~A}$ decomposition of the initial $\mathrm{Di}=1$ group by level of participation in the program is presented in Additional file 1: Figure S1.

${ }^{23}$ The estimation for the different subpopulations compares individuals from the treatment and control groups within each specific subpopulation. So, for example, the ITT coefficients of Santo Domingo compare individuals from the treatment group in Santo Domingo with individuals from the control group in Santo Domingo. This applies even to the type of course subpopulations, as there are individuals both in the treatment and the control groups for each type of course.

${ }^{24}$ This is consistent with the results from the first evaluation of the program, and with evaluations of similar programs that report impacts on the probability of getting formal employment (Attanasio et al. (2011), Ibarrarán and Rosas (2009)).

${ }^{25}$ The control group mean reveals that Dominican youth are very optimistic to begin with. Hence, improvements in the treatment group are with respect to a very high starting point.

${ }^{26}$ In this context in which youth have not even completed high school, expectations of a better education level refer to going back to school or continuing to take training courses of the sort of the JE program.

${ }^{27}$ Hence, if one were to carry out a cost-benefit analysis, specifically, of the raising perceptions and expectations "component" of the JE program, it would be necessary to assume or measure a quantitative relation between: i) the changes in the "expectation scales" and the changes in some selected behaviors; and ii) the changes in these selected behaviors and the changes in labor market outcomes. Then it should be possible to compare the costs of providing the "component" to the benefits of obtaining the corresponding changes in labor market outcomes. In a way, it would be like doing a general cost-benefit analysis of the program, but weighting it up by the fraction attributable to this "component".

${ }^{28}$ The Rosenberg Scale was first presented in 1965 and later revised in 1989, and it has been validated in 53 countries and translated into 28 languages. See Rosenberg (1989).

${ }^{29}$ The Grit Scale was created in 2007 and later revised in 2009. See Duckworth et al. (2007).

${ }^{30}$ See Hill et al. (2007) for a guide on interpreting effect sizes in research.

${ }^{31}$ It is possible that some of the effects on life skills are due to the internship and not only to the life skills training component. This is an important area for future research, as the interaction between life skills and training may have important policy implications in terms of which elements of the training package are more effective.

${ }^{32}$ We use only the individuals assigned to the control group. The objective of limiting the sample is to avoid the endogeneity that would arise when using the entire sample, 
as individuals assigned to the treatment could have both higher scores in the noncognitive scales and higher levels of employment.

${ }^{33} \mathrm{We}$ also tried using additional dependent variables, such as formality and earnings, and did not find any impacts. Similarly, we excluded some of the control variables and obtained equivalent results.

${ }^{34}$ As with perceptions and expectations, life skills are not a program objective by themselves, but a channel through which it should be possible to increase youth employability. As a result, they have an economic value to the extent that they are associated with improvements in labor market outcomes. The regressions here presented show that such relationship between like skills and employment needs to be further studied; not only to understand it in itself, but to enable the completion of cost-benefit analyses related to non-cognitive skills training activities.

${ }^{35}$ See Hirshleifer et al. (2014) for a recent discussion on this issue.

${ }^{36}$ These computations use the ITT estimates reported in the paper. One could also do the analysis based on the LATE or Treatment-on-the-treated estimates shown in the Additional file 1, which basically double the impacts, thus reducing the time required to recover the costs in half. However, given that the interpretation of LATE is local, referring only to those that take the course because they won the lottery, we prefer to be conservative and use the standard intention-to-treat estimates for cost/ benefit considerations.

${ }^{37}$ The lower number is computed based on the need to train twenty female teenagers in order to prevent one pregnancy, with a cost (excluding transfers) of US $\$ 500$ per trainee. The upper bound is based on the actual composition of trainees, in which only $16 \%$ of trainees were teenage females. If the LATE estimates shown in the Additional file 1 are taken at face value, the cost-range would be about half (US\$5,000-US\$33,000).

\section{Additional file}

Additional file 1: Figure S1. Program Participation Stages. Table S1. Original and realized for the follow-up survey. Table S2. Characteristics of the Complier and Non-Complier Groups. Table S3. LATE estimation on selected labor market outcomes. Table S4. LATE estimation on pregnancy. Table S5. LATE estimation on expectations. Table S6. LATE estimation on the CPS Scale.

\section{Competing interests}

The IZA Journal of Labor \& Development is committed to the IZA Guiding Principles of Research Integrity. The authors declare that they have observed these principles.

\section{Acknowledgements}

This project is a collaborative effort involving many people. First, we want to recognize the work and commitment to the evaluation agenda of the program of José Luis Polanco, director of the project coordinating unit (PCU) at the Ministry of Labor in the Dominican Republic. He and his team have taken the evaluation very seriously posing the relevant questions and taking action to improve the project based on the evaluation findings. We are especially thankful for the collaboration of Douglas Hasbun from the PCU. Additionally, we have benefited from the inputs with key staff at the Ministry of Labor, in particular Deyanira Matrillé from the Labor Market's Observatory, Sarah Pimentel from the National Employment Service, and María de Lourdes Cabrera, the Ministry's General Director for Employment. We also recognize the ongoing support of the Minister of Labor Francisco Dominguez and of the Director of the INFOTEP, the national training institute, without whom the implementation of the program and the rigorous evaluation would not have been possible. This document is part of a broad evaluation agenda in which Paloma Acevedo and Carlos Asenjo from the World Bank and Sebastián Martinez from the IDB have played a key role. We acknowledge excellent comments and suggestions from Guilherme Sedlacek, Norbert Schady, an anonymous peer reviewer for the IDB WP series, and from seminar participants at the 2011 IZA conference in Labor and Development, 
and at the Inter-American Development Bank - 3ie International Conference on Impact Evaluation. The views expressed in this paper are those of the authors and should not be attributed to the Inter-American Development Bank.

Responsible editor: David Lam

\section{Author details}

IInter-American Development Bank (IDB), Washington, DC and IZA, Bonn, Germany. ${ }^{2}$ Inter-American Development Bank (IDB), Washington, DC, USA. ${ }^{3}$ University of Manchester, Manchester, England. ${ }^{4}$ Professor at the Universidad Autónoma de Santo Domingo, Santo Domingo, Dominican Republic.

Received: 21 July 2013 Accepted: 11 April 2014

Published: 10 Jun 2014

\section{References}

Acero-Gomez E, Campos-Vazquez R (2011) "Teenage Pregnancy in Mexico: Evolution and Consequences". Paper for the World Bank Report "Teenage Pregnancy in Latin America", Washington, DC

Angrist J, Pischke J (2009) Mostly Harmless Econometrics: An Empiricist's Companion. Princeton University Press, Princeton NJ

Ashenfelter O (1978) Estimating the Effect of Training Programs on Earnings. Rev Econ Stat 60:47-50

Attanasio O, Kugler A, Meghir C (2011) Subsidizing Vocational Training for Disadvantaged Youth in Colombia: Evidence from a Randomized Trial. Am Econ J 3(3):188-220

Betcherman GK, Dar A (2004) "Impacts of Active Labour Market Programs: New Evidence from Evaluations with Particular Attention to Developing and Transition Countries.". World Bank Social Protection Discussion Paper 0402, Washington, DC

Brea M (2010) "Interpretación de las Escalas CPS, Rosenberg y Grit y Propuestas de Revisión para Mejorar la Confiabilidad." (Document prepared for the World Bank). Ther World Bank, Washington, DC

Brunello G, Schlotter M (2011) "Non Cognitive Skills and Personality Traits: Labour Market Relevance and their Development in Education and Training Systems." IZA Discussion paper 5743. The Institute for the Study of Labor (IZA), Bonn, Germany, p 5743

Card D, Ibarrarán P, Regalia F, Rosas-Shady D, Soares Y (2011) The Labor Market Impacts of Youth Training in the Dominican Republic. J Labor Econ 29(2):267-300

Dolton PJ, Makepeace GH, Treble JG (1994) "The Youth Training Scheme and the School-to-Work Transition," Oxford Economic Papers, Oxford University Press, 46(4):629-657

Duckworth AL, Peterson C, Matthews MD, Kelly DR (2007) Grit: Perseverance and Passion for Long-Term Goals. J Pers Soc Psychol 92(6):1087-1101

Duflo E, Glennerster R, Kremer M (2008) "Using Randomization in Development Economics Research: A Toolkit". In: Paul Schultz T, John A, Strauss A (eds) Handbook of Development Economics," Elsevier, vol 4, 1st edn

Fazio MV (2011) "Análisis de la percepción de los empleadores acerca de las pasantías y las perspectivas de inserción laboral en esas empresas." BID. Nota Técnica IDB-TN-240. Banco Interamericano de Desarrollo, Washington, DC

Felfe C, Lechner M, Steinmayr A (2011) "Sports and Child Development." IZA Discussion paper 6105. Institute for the Study of Labor (IZA), Bonn, Germany

Gonzalez C, Ripani L, Rosas D (2011) Mejorando las Oportunidades de Inserción Laboral de Jóvenes en América Latina. BID. Nota Técnica,

Heckman J, Lalonde RJ, Smith J (1999) The Economics and Econometrics of Active Labor Market Programs. In: Ashenfelter O, Card D (eds) Handbook of Labor Economics, vol 3A. Elsevier, New York, pp 1865-2097

Heckman J, Stixrud J, Urzua S (2006) The Effects of Cognitive and Noncognitive Abilities on Labor Market Outcomes and Social Behavior. J Labor Econ 24(3):411-482

Hill CJ, Bloom HS, Black AR, Lipsey MW (2007) "Empirical Benchmarks for Interpreting Effect Sizes in Research". MDRC Working Papers on Research Methodology. MDRC, New York, NY

Hirshleifer S, McKenzie D, Almeida R, Ridao-Cano C (2014) "The Impact of Vocational Training for the Unemployed. Experimental Evidence from Turkey," World Bank. Policy Research Working Paper 6807. The World Bank, Washington, DC

Ibarrarán P, Rosas D (2009) Evaluating the Impact of Job Training Programs in Latin America: Evidence from IDB Funded Operations. J Dev Effect 2(1):195-216

Martinez S (2011) "Impacts of the Dominican Republic Youth Employment Program: Hard Skills or Soft Skills", Mimeo. http://siteresources.worldbank.org/INTLM/Resources/390041-1141141801867/2275364-1313438221557/PJE_DR_PPT.pdf Oficina Nacional de Estadística (ONE) (2008) "Madres Adolescentes en República Dominicana".

Rosenberg M (1989) "Society and the Adolescent Self-Image." Revised Edition. Wesleya University Press, Middletown, C.T Thaler R, Sunstein CR (2009) Nudge: Improving decisions about health, wealth and happiness. Penguin, New York Urzua S (2009) Transición Escuela-Trabajo El Rol de las Habilidades y el Sistema Educativo. Report for the Inter-American Development Bank. Inter-American Development Bank, Washington, DC

10.1186/2193-9020-3-10

Cite this article as: Ibarraran et al:: Life skills, employability and training for disadvantaged youth: Evidence from a randomized evaluation design. IZA Journal of Labor \& Development 2014, 3:10 